\title{
Prevalence of carriage of antimicrobial resistant strains of Streptococcus pneumoniae in primary school children in Hong Kong
}

\author{
M. V. BOOST ${ }^{1 *}$, M. M. O’DONOGHUE ${ }^{1}$ AND J. S. DOOLEY ${ }^{2}$ \\ ${ }^{1}$ Department of Nursing \& Health Sciences, The Hong Kong Polytechnic University, Hung Hom, Kowloon, \\ Hong Kong \\ ${ }^{2}$ School of Environmental Studies, University of Ulster, Coleraine, Northern Ireland
}

(Accepted 13 February 2001)

\section{SUMMARY}

A cross-sectional survey was conducted to determine prevalence and assess risk factors for carriage of antibiotic resistant strains of Streptococcus pneumoniae in healthy school children in Hong Kong. Throat swabs were collected from 1455 subjects and written questionnaires providing demographic data and medical history were completed by parents. The overall carriage rate of Streptococcus pneumoniae was $3.5 \%$, of which $49 \%$ were penicillin resistant. High levels of resistance to tetracycline (73\%), erythromycin $(52 \%)$, trimethoprim $(66 \%)$ and ciprofloxacin $(57 \%)$ were observed. Carriage was associated with presence of a younger sibling $(\mathrm{OR}=1.79)$ and use of antibiotics $(\mathrm{OR}=2 \cdot 31)$. High use of day care and small size of housing units did not result in a high rate of carriage. The low rate of carriage may be linked to high use of antibiotics, geographical factors or ethnicity. High rates of antibiotic resistance reflect heavy use of antibiotics by general practitioners.

\section{INTRODUCTION}

Streptococcus pneumoniae is the most important bacterial cause of pneumonia, bacteraemia and otitis media in children and is the third most common cause of meningitis [1-3]. The emergence of antibiotic resistant strains of pneumococci over the last 20 years, has made management of these infections more difficult [4]. Early resistant isolates showed intermediate levels of resistance to penicillin (minimum inhibitory concentration (MIC) $0 \cdot 12-1 \mu \mathrm{g} / \mathrm{ml}$ ) but later, highly resistant isolates (MIC $4-8 \mu \mathrm{g} / \mathrm{ml}$ ) [5], and multiply-resistant pneumococci were reported [6]. Reports show a progressive increase in prevalence once resistant strains are introduced into an area, as observed in Spain between 1980 and 1987 [7, 8]. Resistance to penicillin has been reported in clinical

\footnotetext{
* Author for correspondence.
}

isolates in South East Asia including Japan [9], Taiwan [10,11], and China [12], and an increasing prevalence of penicillin-resistant clinical isolates of pneumococci has been observed in Hong Kong [13]. Resistance rates increased from zero in 1987-8 to $10 \%$ in 1993 [13]. Another study reported 17\% incidence of resistance in pneumococcal isolates [14]. High carriage rates of penicillin-resistant pneumococci in the community have been associated with an increased incidence of clinical infection with resistant strains [4, 15-17]. Healthy children may act as an important reservoir of resistant strains of the organism [18]. Several risk factors for carriage of antibioticresistant strains in children have been described including recent hospital admission, recent antibiotic use and attendance at day-care centres [19-21]. Small size of housing unit and overcrowding have also been identified as risk factors for carriage of pneumococci 
$[21,22]$. The overcrowding and day care risk factors are of particular relevance in Hong Kong, where housing units are small in size and where there is a high rate of use of child care facilities. In addition, antibiotic use by general practitioners is high [23]. There has only been one limited community-based survey of carriage of pneumococci in Hong Kong [23]. The prevalence of antibiotic-resistant strains carried by healthy children in the community in Hong Kong has not been reported. Knowledge of the levels of penicillin resistance in the community would be useful in the management of pneumococcal disease.

The aim of this study was to establish the carriage rate of Streptococcus pneumoniae, and the prevalence of antibiotic-resistant strains in Hong Kong primary school children. It also attempted to determine risk factors associated with carriage of antibiotic resistant strains.

\section{MATERIALS AND METHODS}

\section{Study population}

The reference population was defined as children attending the first year of primary school (primary one) in Hong Kong. As $98 \%$ of the population in Hong Kong is Chinese, the sample was restricted to those of Chinese ethnic origin. The schools used were situated in traditional urban areas, areas of older public housing and in new towns in the New Territories, to provide a representative sample in terms of both locations and socio-economic status. Informed consent to screen the children was sought from parents, who were asked to complete a simple questionnaire on family size, age of siblings of the index child, housing type as an indicator of socioeconomic status, recent travel out of Hong Kong, hospital admissions in the past year, and visits to the doctor and antibiotic use in the preceding 3 months. The questionnaire had been translated into Chinese and validated by a pilot study. Housing type used the definitions of the Census and, in general, families living in private flats or in home ownership schemes would have higher incomes. Public housing indicates rented government owned properties which are only available to those on lower incomes. The temporary housing category indicates homes in government provided housing of small size with very limited facilities. Families may have to stay in these premises for several years whilst waiting for places in public housing.

\section{Study design}

The study was a cross-sectional survey. A representative sample of the primary one school population were screened for carriage of Streptococcus pneumoniae and the prevalence of antibiotic resistance determined in these isolates. The investigation was approved by the Human Subjects Ethics Committee of the Hong Kong Polytechnic University.

\section{Microbiological methods}

Throat swabs collected from each child were placed in transport media and delivered to the laboratory within $1 \mathrm{~h}$. The swabs were inoculated on $5 \%$ blood agar supplemented with $1 \%$ crystal violet and the plates incubated at $37{ }^{\circ} \mathrm{C}$ in $5 \% \mathrm{CO}_{2}$ for $24 \mathrm{~h}$. Streptococcus pneumoniae were identified by colonial morphology, optochin sensitivity and bile solubility. Screening for antibiotic resistance was performed on Mueller Hinton agar with $5 \%$ lysed horse blood by disdiffusion techniques using antibiotic concentrations and breakpoints as specified by the National Committee for Clinical Laboratory Standards (NCCLS) [24]. Susceptibility to the following antibiotics was determined: erythromycin, tetracycline, vancomycin, teicoplanin, rifampicin, trimethoprim, ciprofloxacin, and imipenem. For teicoplanin, trimethoprim, ciprofloxacin and imipenem, interpretation criteria of the Swedish Reference Group for Antibiotics was used [25]. Susceptibility to benzyl penicillin was determined using $1 \mu \mathrm{g}$ oxacillin disks [26]. Isolates with a zone of inhibition $\leqslant 19 \mathrm{~mm}$ were considered resistant and the MICs to penicillin and cefotaxime were then determined by E-test. Cefotaxime is currently used in Hong Kong to treat cases with penicillin resistance.

\section{Statistical methods}

Results were analysed using the SPSS statistical package and Pearson chi square test was performed and odds ratios with $95 \%$ confidence intervals were calculated. Multivariate logistic regression was also performed with carriage of pneumococci as the dependent variable and inclusion of younger siblings, travel, hospitalization, visits to the doctor and use of antibiotics as covariates. This analysis was repeated using carriage of antibiotic resistant strains as the dependent variable.

It was calculated that for the sample size of 1455 , with a carriage rate of $3.5 \%$ and by setting alpha to 
Table 1. Antimicrobial resistance of isolates of Streptococcus pneumoniae

\begin{tabular}{|c|c|c|c|}
\hline $\begin{array}{l}\text { Antimicrobial } \\
\text { agent }\end{array}$ & $\begin{array}{l}\text { No. of strains } \\
\text { resistant }(\%) \\
\text { (penicillin-sensitive } \\
\text { strains) } n=26\end{array}$ & $\begin{array}{l}\text { No. of strains } \\
\text { resistant }(\%) \\
\text { (penicillin-sensitive } \\
\text { strains) } n=25\end{array}$ & $\begin{array}{l}\text { No. of strains } \\
\text { resistant }(\%) \\
\text { (all strains) } n=51\end{array}$ \\
\hline $\begin{array}{l}\text { Sensitive to } \\
\text { all drugs }\end{array}$ & $5(19)$ & - & $5(10)$ \\
\hline Penicillin (IR) & - & $9(36)$ & $9(18)$ \\
\hline Penicillin (R) & - & $14(56)$ & $14(27)$ \\
\hline Tetracycline & $17(65)$ & $20(80)$ & 37 (73) \\
\hline Erythromycin & $10(38)$ & $17(68)$ & $27(52)$ \\
\hline Trimethoprim & $17(65)$ & $17(68)$ & $34(66)$ \\
\hline Ciprofloxacin & $17(65)$ & $12(48)$ & $29(57)$ \\
\hline 1 agent & $6(23)$ & - & $6(12)$ \\
\hline 2 agents & $8(31)$ & $3(12)$ & $11(22)$ \\
\hline 3 agents & $9(34)$ & $8(32)$ & $17(33)$ \\
\hline 4 agents & $3(12)$ & $9(36)$ & $12(24)$ \\
\hline Cefotaxime* & - & $9(36)$ & $9(18)$ \\
\hline
\end{tabular}

$*(\mathrm{MIC} \geqslant 1.0 \mathrm{mg} / \mathrm{ml})$.

0.05 and power to 0.8 , the minimum odds ratio detectable was $1 \cdot 67$.

\section{RESULTS}

\section{Study population}

1970 children from 19 schools were invited to participate. 1470 parents completed the consent form and questionnaire, and samples were collected from 1455 children, a response rate of $73 \%$. Nine children were absent on the day of sampling and six refused to have a swab taken. Participation rates differed little between schools (range 68-80\%) and were not linked to location. Some parents who had declined to participate completed the questionnaire. 50 of these were analysed and there appeared to be no difference between those who participated and those who refused. A few who refused gave the reason of previous unpleasant experience with throat swab, but most simply declined. Between 17 and 121 children were screened in each school (mean 77). The mean age was 77 months, median 72 months. The sex distribution was approximately equal (51\% girls, $49 \%$ boys).

\section{Carriage of Streptococcus pneumoniae}

The prevalence of carriage of Streptococcus pneumoniae was $3.5 \%$ (49 out of 1455). A total of 51 strains were isolated as 2 children carried 2 strains. 25 (49\%) of the 51 strains were resistant to penicillin, of which,
$14(27.5 \%)$ were highly resistant to penicillin. Cefotaxime MIC was determined and of strains displaying high level penicillin resistance, $9(64 \%)$ showed resistance (MIC $\geqslant 1.0 \mu \mathrm{g} / \mathrm{ml}$ ). Only 5 strains $(10 \%)$ were sensitive to all drugs tested and all penicillin resistant strains displayed resistance to at least one other drug. Resistance to tetracycline, ciprofloxacin and trimethoprim was observed alone, but erythromycin resistance was always in combination (Table 1). Although there was some reduction in zone size, no strains showed resistance to imipenem using the Swedish Reference criteria [25].

\section{Epidemiological characteristics}

Several factors appeared to be associated with carriage, but the relatively small numbers of carriers resulted in wide confidence intervals (Table 2). Only the presence of younger sibling(s) in the family was clearly associated with increased risk of carriage (OR $1 \cdot 88$, CI $1.04-3 \cdot 40 ; P=0.036$ ). The presence of only older siblings appeared to be protective, with confidence intervals just above the value for significance (OR 0.56, CI 0.30-1.02; $P=0 \cdot 056$ ).

There did not appear to be a relationship between the age of the child and the risk of carriage within the age range sampled, as prevalence in those $>77$ months was $3 \cdot 4 \%$ and in those $>72$ months, $3.5 \%$.

There was no significant association between housing type and either carriage of pneumococci or presence of resistant strains of Streptococcus pneumo- 
Table 2. Associations between family size, siblings, travel, hospitlization, visits to the doctor and antibiotic usage and carriage of Streptococcus pneumoniae

\begin{tabular}{|c|c|c|c|c|}
\hline \multirow[b]{2}{*}{ Variable } & \multicolumn{2}{|c|}{ Streptococcus pneumoniae } & \multirow{2}{*}{$\begin{array}{l}\text { Crude OR, } \\
95 \% \text { CI }\end{array}$} & \multirow{2}{*}{$\begin{array}{l}\text { Adjusted OR, } \\
95 \% \text { CI }\end{array}$} \\
\hline & Present $(\%) n=49$ & Absent $(\%) n=1406$ & & \\
\hline Older siblings & $16(32)$ & $645(46)$ & $0 \cdot 56(0 \cdot 30-1 \cdot 02)$ & - \\
\hline No siblings & $11(22)$ & $366(26)$ & $0 \cdot 81(0 \cdot 41-1 \cdot 58)$ & - \\
\hline Has siblings & $38(77)$ & $1025(74)$ & $1 \cdot 23(0 \cdot 61-2 \cdot 34)$ & - \\
\hline Younger siblings & $24(49)$ & $484(35)$ & $1 \cdot 79(1 \cdot 01-3 \cdot 15)$ & $\begin{array}{l}1 \cdot 88(1 \cdot 04-3 \cdot 40) \\
\quad(\text { carriage of pnc) }\end{array}$ \\
\hline Travel & $11(23)$ & $292(21)$ & $1 \cdot 15(0 \cdot 51-2 \cdot 27)$ & $\begin{array}{l}1 \cdot 13(0.57-2 \cdot 27) \\
\quad(\text { carriage of pnc) }\end{array}$ \\
\hline Hospitalization & $2(4 \cdot 2)$ & $22(1 \cdot 6)$ & $2 \cdot 76(0 \cdot 63-12 \cdot 02)$ & $\begin{array}{l}3 \cdot 56(0.77-16.42) \\
\quad(\text { carriage of pnc) }\end{array}$ \\
\hline Visit to doctor* & $15(33)$ & $546(39)$ & $0 \cdot 73(0 \cdot 39-1 \cdot 38)$ & $\begin{array}{l}0 \cdot 71(0 \cdot 23-2 \cdot 13) \\
\quad(\text { carriage of pnc })\end{array}$ \\
\hline Visit to doctor $\dagger$ & $10(43)$ & $551(39)$ & $1 \cdot 92(0 \cdot 60-6 \cdot 15)$ & $\begin{array}{l}2 \cdot 49(0 \cdot 13-46 \cdot 27) \\
\quad(\text { carriage of PRSP })\end{array}$ \\
\hline Use of antibiotic* & $14(34)$ & $473(30)$ & $1 \cdot 12(0 \cdot 72-1 \cdot 75)$ & $\begin{array}{l}1 \cdot 17(0 \cdot 637-2 \cdot 21) \\
\quad(\text { carriage of pnc) }\end{array}$ \\
\hline Use of antibiotic $\dagger$ & $9(39)$ & $478(34)$ & $2 \cdot 31(0 \cdot 63-8 \cdot 39)$ & $\begin{array}{l}1.93(0 \cdot 58-6 \cdot 38) \\
\quad(\text { carriage of PRSP })\end{array}$ \\
\hline
\end{tabular}

* All isolates, $\dagger$ Penicillin-resistant isolates.

Older siblings $=$ child has older siblings only. Younger siblings $=$ child has younger siblings. Hospitalization $=$ hospitalization within last year for any reason. Visit to doctor $=$ parent reported visit within last 3 months. Use of antibiotic $=$ parent reported antibiotic prescribed for the child within last 3 months.

$\mathrm{pnc}=$ pneumococcus; PRSP $=$ Penicillin resistant Streptococcus pneumoniae.

Table 3. Relationship between housing type and carriage of Streptococcus pneumoniae

\begin{tabular}{lll}
\hline \hline Housing type & $\begin{array}{l}\text { Prevalence of } \\
\text { carriage }(\%)\end{array}$ & $\begin{array}{l}\text { Percentage of penicillin } \\
\text { restraint strains }(\%)\end{array}$ \\
\hline Private flat & 4.7 & 43 \\
Home Ownership & 3.0 & 66 \\
Scheme & & \\
Public & 2.6 & 45 \\
Temporary & 6.9 & 25 \\
\hline \hline
\end{tabular}

niae (Table 3). The sample closely matched the percentages living in the four housing types reported by the most recent census. The highest isolation of pneumococci was from children living in temporary housing, but numbers of children living in this type of housing was only $4 \%$ of the total tested.

The rate of carriage differed between individual schools ranging from $0-13 \%$ and there appeared to be clustering of carriage of Streptococcus pneumoniae in some schools $\left(\chi^{2}=67 \cdot 71 ; P=<0.001\right)$. In schools where carriage was found, both sensitive and resistant strains were isolated.

\section{DISCUSSION}

This study showed a low rate of carriage of Streptococcus pneumoniae in primary one schoolchildren in Hong Kong $(3.5 \%)$. This figure is lower than the carriage rate of $10.8 \%$ reported in the limited study performed by Sung et al. [23]. However, their study population ranged in age from 2 months to 5 years, and previous workers have shown that higher carriage rates are found in younger children [27].

The association observed in this study between carriage and younger siblings may reflect the higher rates of carriage usually seen in the younger age group. However, an increase of carriage in early school years has been reported [28], which may reflect contact with other children who are carriers. Having no siblings or only older siblings would tend to reduce exposure to younger children explaining the lower carriage rates. Although many studies have reported higher rates of carriage in children in pre-school and primary school [16, 19], a low carriage rate in young children was reported in a recent large study in Italy [28]. These authors suggested the low rate may be due to sampling of healthy children. This may also explain 
the low carriage rate in our study, as sampling was performed on children attending school. Few children in either the Italian or the present study had been hospitalised.

Many studies [7, 8, 14, 29, 30] have reported an increase in the prevalence of antibiotic resistance of laboratory isolates in the last 20 years. These studies fail to address the prevalence of antibiotic-resistant pneumococci in the general population. Several studies described as population-based studies were connected to outbreaks or were associated with one institution. Variations in study design make it difficult to compare prevalence rates between countries. Studies performed in Spain [16], Australia [31] and Canada [27] have reported prevalence rates of penicillin resistance in pneumococcal strains to be $35.9 \%, 30 \%$ and $17 \%$. In contrast, a UK study of similar design to this study, found a much lower rate of resistant strains $(2 \cdot 8 \%)$ [19]. This may reflect lower rates of antibiotic use in UK. The results of the present survey have shown that $49 \%$ of strains are antibiotic resistant, which is one of the highest reported rates in a community study. The proportion of strains with high level resistance was $28.5 \%$ which is much higher than that of the UK study [19] and that of Australian children in day care [31]. Penicillin-resistance was reported as $17.4 \%$ in clinical isolates of Streptococcus pneumoniae in Hong Kong but this was not differentiated into high and intermediate levels of resistance [14].

Levels of resistance to other antimicrobials were also high and all penicillin resistant strains were resistant to at least one other agent. The high level of resistance to erythromycin in the isolates $(52 \%)$ reflects that seen in clinical isolates in Hong Kong (68\%) [29].

Some studies have reported that carriage of pneumococci, in particular resistant strains [19], is associated with travel overseas. In this current study, travel did not seem to be associated with pneumococcal carriage or antibiotic resistance. However, as the number of children who had travelled was relatively small, and mainly to nearby Southern China, the effect of travel may have been missed. Hospitalization has been shown to be associated with carriage of penicillin-resistant strains in children [20], but although there was an indication of increased risk of carriage associated with hospitalization (OR 3.56), this did not achieve significance as only 24 children $(1.6 \%)$ had been hospitalized. Several studies have shown an association between antibiotic use and carriage of resistant strains of Streptococcus pneumoniae [22,32]. Investigation of this association was made difficult because many of the parents were unaware of the types of drugs prescribed for their children. Of those reporting antibiotic use, there did appear to be an association (OR 1.17 for all isolates, OR 1.93 for resistant isolates) but this did not reach statistical significance due to the small numbers.

Socio-economic factors and poor housing conditions have been shown to be associated with higher rates of carriage of Streptococcus pneumoniae [27, 33], but there were no significant associations with any housing type although rates did appear higher in temporary housing. It is possible that the lower level of resistant strains in children living in temporary housing reflects lower use of antibiotics. The percentage of resistant strains was highest in home ownership scheme housing. This may be due to the higher socio-economic status and ease of access to doctors of this group, who may seek medical attention more often. However, small numbers of isolated pneumococci prevented any valid statistical testing. Other studies on Vietnamese children living in detention camps in Hong Kong [23] in very overcrowded conditions, have shown higher rates of carriage. The effect of socioeconomic factors in the current study may be masked, as the carriage rate was low overall and, although overcrowding has decreased, there is still a high density of people in most housing units in Hong Kong. The low rate of carriage reported here is in contrast to the situation elsewhere, where high rates of carriage have been associated with small size of housing units [33].

Use of child care facilities has been identified as a risk factor for carriage in other studies [20, 27, 34], but although virtually all children in this study had attended kindergarten, there was a low rate of carriage.

It is difficult, therefore, to explain the low rate of carriage of pneumococci in Hong Kong. Genetic factors have been suggested as of possible importance in determining carriage, and were suggested as a possible additional factor in the comparison of Hong Kong and Vietnamese children [23]. Further studies of other groups of children living in Hong Kong should be performed to determine if the environment or ethnicity affect carriage in this area.

It has been suggested that high rates of antibiotic use may eradicate carriage of pneumococci from most children, but may select for resistant strains when these are present [35]. It is generally considered that 
there is a high rate of prescription of antibiotics in Hong Kong [23, 36]. This may account for the change in direction of the risk factor for visits to the doctor in carriage of antibiotic resistant strains, and the low rate of carriage together with a high level of antibiotic resistance observed in this study. Longitudinal studies on the effect of antibiotics on carriage of pneumococci may reveal this relationship. Restrictive strategies on antibiotic usage may be considered to reduce the high rates of carriage of resistant pneumococci.

\section{ACKNOWLEDGEMENTS}

This work was supported by Research Funding from the Department of Nursing and Health Sciences, The Hong Kong Polytechnic University. We are grateful for the co-operation of Mr John Leung of the Tung Wah Group of Hospitals for arranging the participation of schools and the head-teachers of the schools for their help in arranging sample collection.

The authors would like to thank Professor S. K. Lo for advice on statistical analysis, Ms Irene Wu for help in specimen collection, and Ms Lorraine Leung for technical assistance.

\section{REFERENCES}

1. Gray BM, Converse GM, Dillon HC. Epidemiologic studies of Streptococcus pneumoniae in infants: acquisition, carriage and infection during the first 24 months of life. J Infect Dis 1980; 142: 923-33.

2. Klein JO. The epidemiology of pneumococcal disease in infants and children. Rev Infect Dis 1981 ; 3: 246-53.

3. Leiberman A, Dagan R, Leibovitz E, Yagupsky P, Fliss DM. The bacteriology of the nasopharynx in childhood. Int J Ped Otorhinolaryngol 1999; 49 (Suppl I): SI51-3.

4. Klugman KP. Pneumococcal resistance to antibiotics. Clin Microbiol Rev 1990; 3: 171-96.

5. Appelbaum PC, Bhamjee A, Scragg JN, Hallett AF, Bowen AJ, Cooper RC. Streptococcus pneumoniae resistant to penicillin and chloramphenicol. Lancet 1977; ii: $995-7$

6. Jacobs MR, Koornhof HJ, Robins-Browne RM, et al. Emergence of multiply resistant pneumococci. N Engl J Med 1978; 299: 735-40.

7. Fenoll A, Martin Bourgon C, Munoz R, Vicioso D, Casal J. Serotype distribution and antimicrobial resistance of Streptococcus pneumoniae isolates causing systemic infections in Spain, 1979-1989. Rev Infect Dis 1991; 13: 56-60.

8. Linares $\mathrm{J}$, Pallares $\mathrm{R}$, Alonso $\mathrm{T}$, et al. Trends in antimicrobial resistance of clinical isolates of Streptococcus pneumoniae in Bellvitge Hospital, Barcelona, Spain (1979-1990). Clin Infect Dis 1992; 15: 99-105.
9. Yoshida R, Kaku M, Kohno S, et al. Trends in antimicrobial resistance of Streptococcus pneumoniae in Japan. Antimicrob Agents Chemother 1995; 39: 11968.

10. Chiou CCC, Liu YC, Huang TS, et al. Extremely high prevalence of nasopharyngeal carriage of penicillinresistant Streptococcus pneumoniae among children in Kaohsiung, Taiwan. J Clin Microbiol 1998; 36: 1933-7.

11. Hseuh PR, Chen HM, Lu YC, Wu JJ. Antimicrobial resistance and serotype distribution of Streptococcus pneumoniae strains isolated in Southern Taiwan. $\mathbf{J}$ Formos Med Assoc 1996; 95: 29-36.

12. Wang H, Huebner R, Chen M, Klugman K. Antibiotic susceptibility patterns of Streptococcus pneumoniae in China and comparisons of MICs by agar dilution and E-test methods. Antimicrob Agents Chemother 1998; 42: 2633-6.

13. Lee YS. Emergence of pneumococci with reduced susceptibility to antibiotics in Hong Kong. J Hong Kong Med Assoc 1993; 45: 49-52.

14. Ling JM, Cheng AF. Antimicrobial resistance of clinical isolates from 1987 to 1993 in Hong Kong. Hong Kong Med J 1995; 1: 212-8.

15. Istre GR, Tarpay M, Anderson M, Pryor A, Welch D, $\&$ the Pneumococcus Study Group. Invasive disease due to Streptococcus pneumoniae in an area with a high rate of relative penicillin resistance. J Infect Dis 1987; 156: $732-5$.

16. Perez JL, Linares J, Bosch J, Lopez de Goicoechea MJ, Martin R. Antibiotic resistance of Streptococcus pneumoniae in childhood carriers. J Antimicrob Chemother 1987; 19: 278-80.

17. Leibovitz E, Raiz S, Piglansky L, et al. Resistance patterns of middle ear fluid isolates in acute otitis media recently treated with antibiotics. Pediatr Infect Dis J 1998; 17: 463-9.

18. Robins-Browne RM, Kharsany AB, Koornhof HJ. Antibiotic resistant pneumococci in hospitalised children. J Hyg 1984; 93: 9-16.

19. Ridgeway EJ, Tremlett CH, Allen KD. Capsular serotypes and antibiotic sensitivity of Streptococcus pneumoniae isolated from primary-school children. $\mathbf{J}$ Infect 1995; 30: 245-51.

20. Barnes DM, Whittier S, Gilligan PH, Soares S, Tomasz A, Henderson FW. Transmission of multidrug-resistant serotype $23 \mathrm{~F}$ Streptococcus pneumoniae in group day care: evidence suggesting capsular transformation of the resistant strain in vivo. J Infect Dis 1995; 171: 890-6.

21. Gillespie SH. Aspects of pneumococcal infection including bacterial virulence, host response and vaccination. J Med Microbiol 1989; 28: 237-48.

22. Guillemot D, Carbon C, Balkau B, et al. Low dosage and long treatment duration of $\beta$-lactam: risk factors for carriage of penicillin-resistant Streptococcus pneumoniae. JAMA 1998; 279: 365-70.

23. Sung RYT, Ling JM, Fung SM, Oppenheimer SJ, Crook DW, Cheng AF. Carriage of Haemophilus influenzae and Streptococcus pneumoniae in healthy 
Chinese and Vietnamese children in Hong Kong. Acta Paediatr 1995; 84: 1262-7.

24. National Committee for Clinical Laboratory Standards. Performance standards for antimicrobial disc susceptibility tests: Document M2-A5. Villanova, PA: NCCLS, 1993.

25. Olsson-Liljequist B, Larsson P, Walder M, Miorner H. Antimicrobial susceptibility testing in Sweden: III. Methodology for susceptibility testing. Scand J Infect Dis Suppl 1997; 105: 13-23.

26. Swenson JM, Hill BC, Thornsberry C. Screening pneumococci for penicillin resistance. J Clin Microbiol 1986; $24: 749-52$.

27. Kellner JD, Ford-Jones EL, Members of the Toronto Child Care Centre Study Group. Streptococcus pneumoniae carriage in children attending 59 Canadian child care centers. Arch Pediatr Adolesc Med 1999; 153: 495-502.

28. Principi N, Marchisio P, Schito GC, Mannelli S, \& The Ascanius Project Collaborative Group. Risk factors for carriage of respiratory pathogens in the nasopharynx of healthy children. Pediatr Infect Dis J 1999; 18: 517-23.

29. Kam KM, Luey KY, Fung SM, Yiu PP, Harden TJ, Cheung MM. Emergence of multiple-antibiotic-resistant Streptococcus pneumoniae in Hong Kong. Antimicrob Agents Chemother 1995; 39: 2667-70.
30. Baquero F. Evolving resistance patterns of Streptococcus pneumoniae: A link with long-acting macrolide consumption? J Chemother 1999; 11: 35-43.

31. Skull SA, Shelby-James T, Morris PS, et al. Streptococcus pneumoniae antibiotic resistance in Northern Territory children in day care. J Paediatr Child Health 1999; 35: 466-71.

32. Arnold KE, Leggiadro RJ, Breiman RF, et al. Risk factors for carriage of drug-resistant Streptococcus pneumoniae among children in Memphis, Tennessee. $\mathbf{J}$ Pediatr 1996; 128: 757-64.

33. Aniannsson G, Alm B, Andersson B, et al. Nasopharyngeal colonization during the first year of life. J Infect Dis 1992; 165 (Suppl 1): S38-42

34. Radetsky MS, Johansen TL, Lauer BA, et al. Multiply resistant pneumococcus causing meningitis: its epidemiology within a day-care centre. Lancet 1981; ii: 771-3.

35. Dagan R, Melamed R, Muallem M, Piglansky L, Yagupsky P. Nasopharyngeal colonization in Southern Israel with antibiotic-resistant pneumococci during the first two years of life: relation to serotypes likely to be included in pneumococcal conjugate vaccines. J Infect Dis 1996 ; 174: 1352-5.

36. Chan CSY. Patients' preferences in consultations for upper respiratory tract infections. HK Practitioner 1997; 19: 171-6. 